\title{
Early Prediction of Attachment Security: A Multivariate Approach*
}

\author{
TONI C. ANTONUCCI \\ The University of Michigan \\ MARY J. LEVITT \\ Florida International University
}

\begin{abstract}
This study was designed to explore the possibility that variations in attachment security exhibited by infants in the Ainsworth Strange Situation at 13 months could be predicted from the behavior of mothers and infants in an analogous preseparation, separation and reunion situation at 7 months, when specific attachments begin to emerge. Data obtained on a large sample of 7-month-old infants and their mothers were subjected to factor analyses to identify important variables and interrelationships. Based on these analyses, variables were incorporated into multiple discriminant function analyses of a subsample of infants, with infant attachment classification at 13 months as the criterion.

The results suggest that a) attachment security at the end of the first year can be significantly predicted from a brief observation of mother-infant interaction at seven months; b) predictability is influenced by observational context (e.g., preseparation vs reunion); and c) multivariate procedures are useful in detecting relationships and continuities among attachment indices.

attachment prediction mother-infant interaction attachment security strange situation
\end{abstract}

The search for continuities in development is often a perplexing and frustrating experience. This is especially true when the search is for continuity in multidimensional, amorphously defined constructs regarding nonobservable structures and processes manifest in behavior that is expected to undergo transformations in the course of development (Lewis \& Starr, 1979). The example par excellence of this class of developmental constructs is the concept of attachment (Bowlby, 1969; Ainsworth, 1973). It has been suggested that specific behaviors thought to reflect the infant's attachment to the caretaker have little predictive value when taken singularly and without regard to context (e.g., Coates, Anderson, \& Hartup, 1972b; Masters \& Wellman, 1974; Waters, 1978). Frequency measures of such attachment behaviors as smiling, vocalizing, and crying evidence little consistency from one day to the next, much less over longer periods of several weeks or months. The exception to this instability of measurement may be proximity seeking and contact behavior (Coates et al., 1972b; Waters,

* The authors thank Elaine Wethington for her tireless assistance with the analysis of these data. These data were collected while both authors were at Syracuse University. Analyses were conducted and this report prepared while the authors were at The University of Michigan and Florida International University. Requests for reprints should be sent to Toni C. Antonucci, Institute for Social Research, The University of Michigan, 426 Thompson Street, Ann Arbor, MI 48106. 
1978). It has also been noted that intercorrelations among attachment behaviors tend to be moderate at best (Coates, Anderson \& Hartup, 1972a; Masters \& Wellman, 1974).

Ainsworth and her colleagues have proposed that both the presence of an attachment relationship and of individual differences in the quality or security of the relationship are reflected not in intercorrelations of attachment behaviors, nor in continuity of discrete behavior frequencies, but rather in the contextually dependent organization of these behaviors with respect to the attachment figure (Ainsworth, Blehar, Waters, \& Wall, 1978; Sroufe \& Waters, 1977; Waters, 1978). This view is reflected in the design of the Strange Situation (Ainsworth \& Wittig, 1969) that has become a standard technique for measuring attachment in infants from approximately 12 to 24 months. Within the context of the sequence of separations, reunions, and encounters with a stranger involved in this situation, individual variations in the organization of attachment behaviors are revealed, particularly in sequences involving reunion with the mother following separation. Three major patterns of behavior have been noted by Ainsworth and her colleagues. Very briefly, the Type A motheravoidant pattern involves ignoring or avoiding the mother during the reunion episodes. The Type B securely attached pattern is evidenced by infants who are able to use the mother as a secure base for exploration, who greet her warmly at reunions, and/or who seek and maintain contact with her when stressed. The Type $C$ pattern reflects an ambivalent angry infant, who often seems to be intensely upset by separation from the mother and who simultaneously seeks contact with her and pushes her away at her return.

The robustness of these classifications over time has been affirmed by Waters (1978) in a longitudinal study of infants from 12 to 18 months. In addition, differential behavior in the Strange Situation in infancy has been predictive of differences in play and problem-solving behavior (Matas, Aiend, \& Sroufe, 1978), social compliance (Londerville \& Main, 1981), social responsiveness (Main \& Weston, 1981), and several measures of ego resiliency and curiosity (Arend, Gove, \& Sroufe, 1979) in 2- to 5-year-old children.

Given the potential utility of the A-B-C classification system, it should be profitable to determine whether there are antecedent predictors of Strange Situation outcomes for at least two reasons: (a) to add to the rather sparse body of knowledge on the relationship between early mother-infant interaction and individual differences in attachment security, and (b) to aid in the development of diagnostic indicators of disturbance in the attachment relationship at as early an age as possible.

Ainsworth and her colleagues report that early correlates of 12-month classification were found in longitudinal home observations of the sample of 26 infants who were among the first to be assessed with the Strange Situation procedure. Among the maternal measures related significantly to infant attachment classification were ratings of the mother's responsiveness to infant signals, her behavior with respect to close bodily contact with her infant, and, 
in the early months, the contingency of her pacing in face-to-face or feeding interactions, i.e., the degree to which she allowed the infant to take the lead in these interactions. Securely attached infants were more likely to be discriminative in their behavior toward the mother and a stranger at three months than were insecurely attached infants; they were less likely to cry when their mother left the room, and more likely to respond positively to both close bodily contact with mother and to termination of that contact. These examples are by no means exhaustive of the numerous correlations reported by Ainsworth and her colleagues; for a thorough review, consult Ainsworth et al. (1978). The reported findings are based on data obtained within the first and last quarters of the infants' first year.

The question addressed by the present study was whether variables distinguishing securely and insecurely attached infants could be detected within the context of a laboratory separation and reunion situation at a time when attachment behaviors focused on specific figures, such as the mother, are hypothesized to emerge; that is, at approximately seven months (Bowlby, 1969; Schaffer \& Emerson, 1964). Toward this end, a large number of motherinfant dyads were observed in a playroom when the infants were between $61 / 2$ and $7 \frac{1}{2}$ months old. Both infant and maternal behaviors were videotaped in a 15-min preseparation and a 3-min reunion episode. Infant behaviors were also recorded during a 2-min separation. The security of the infant's attachment to the mother was assessed at 13 months within the context of the Strange Situation for a subset of this sample. Because of age (at least half the sample were over 13 months when we began the second portion of the study), time constraints, and other pragmatic considerations, it was not possible to assess the entire sample at 13 months.

It was hypothesized that some continuity would be evident between the behavior of infants and mothers toward each other during the earlier observation and the infants' subsequent attachment classification. Given the exploratory nature of this study, however, it was not immediately apparent which behaviors or combinations of behaviors would be predictive. Consequently, several potentially interesting behaviors were coded and the relationships among these behaviors were assessed via factor analysis. Correlational analyses, including factor analytic techniques, have been used previously by attachment researchers to organize data obtained in home observations (Blehar, Lieberman, \& Ainsworth, 1977; Stayton \& Ainsworth, 1973) and to relate that behavior to individual differences in attachment security. However, the samples providing data for these analyses were quite small (26 or less) and Masters and Wellman (1974) have questioned the reliability of correlational analyses in attachment research based on small numbers of infants. Lewis and Starr (1979), on the other hand, view multivariate procedures as highly appropriate to the task of illuminating continuity in developmental constructs such as attachment, provided that large samples of subjects are available. As this was the case in the current study, and since the exploratory nature of the study 
precluded a priori assumptions about the organization or patterning of the infant's behavior toward the mother in the seven-month situation, the data obtained were ideally suited to multivariate analysis.

\section{METHOD}

\section{Sample}

The initial sample consisted of 166 white, middle-class mother-infant pairs living in and around a medium-sized northeastern city. The infants ranged in age from 6.5 to 7.5 months. Names of potential participants were obtained through birth announcements published in the local newspapers. Mothers were contacted by letter and subsequently by telephone. Of those contacted, approximately $75 \%$ agreed to participate in the study. Complete data were obtained for 147 mother-infant dyads ( 77 girls; 70 boys). Only one infant failed to complete the observation sequence. Data for the remaining infants were lost primarily through equipment malfunction. Forty-seven mother-infant pairs were observed again at 13 months. Eighty mothers had been requested to return with their infants but many of these were unable to do so within the time frame of the study. Only a few mothers said they did not want to return.

\section{Observational Setting}

For both the initial seven-month study and the 13-month follow-up, infants and their mothers were observed in a $3.66 \mathrm{~m} \times 5.03 \mathrm{~m}$ playroom. A small observation room containing videotape equipment was located adjacent to the playroom. All observations were recorded on videotape through a one-way mirror.

\section{Procedure}

At 7 months, the procedure consisted of a free play period followed by a brief separation and reunion sequence. Infants returning at 13 months were observed within the context of the Ainsworth Strange Situation (Ainsworth \& Wittig, 1969). Details of both procedures are reported.

Observation 1: Mothers and Infants at 7 Months. Upon arrival at the laboratory, each mother was escorted with her infant to the playroom, which contained a sofa, a table, some current magazines, and several toys. The mother was asked to make herself comfortable during a brief warm-up period, and to leave the room at the sound of a knock. Instructions to mothers were minimized in an attempt to provide as naturalistic a situation as possible in the laboratory.

Following the 15 -min preseparation period, mothers were signaled to leave the playroom. They were brought into the observation room where they could view their infants during the separation period. At the end of the 2-min separation episode, mothers were asked to return to the playroom for a period of three minutes. 
Response Measures for Observation 1. Both maternal and infant behaviors were recorded. Maternal variables for both the preseparation and reunion phases included vocalizing, looking, smiling, approaching, touching, playing, and noninteractive neutral behaviors (e.g., doing nothing, staring into space) and reading. Infant behaviors included vocalizing, looking (at mother or door), smiling, approaching or following (at separation), touching, playing alone, playing with mother, neutral behaviors, crying/fussing and searching (during separation). Proximity and contact avoidance (e.g., crawling, leaning or turning the head away from the mother to avoid engagement with her) was coded, but there were no incidences of this behavior for any of the 7-monthold babies.

Behaviors were coded from videotape recordings by trained observers. At 10-s intervals, the occurrence of any of the previously mentioned behaviors was noted. For each interval, observers also noted whether or not mother and infant were engaged in mutual interaction; i.e., regardless of the particular behaviors, this measure indexed whether any incident involving reciprocal interaction between mother and baby occurred during the interval. Such incidents as the infant's responding to the mother's of fer of a toy or the mother's responding to her baby's cry are examples of those scored as interactive. Reliability was established by having three observers code simultaneously 10 tapes chosen at random (after all data had been collected) and calculating for each behavior a percentage of agreement ratio for each observer in comparison to a fourth coder whose reliability had previously been established. Reliability scores thus obtained ranged from .943 for mother smiling to .987 for mother approaching. The mean reliability for mother behaviors for the three observers was quite high at $\mathbf{. 9 5 5}$. Reliability for the infant behaviors ranged from .860 for looking to 1.00 for crying. The mean reliability score for infant behaviors for the three observers was .958 . A reliability of .871 was achieved for the mutual interaction measure.

Observation 2: Infants at 13 Months. Infants who returned for the follow-up study were observed in the Ainsworth Strange Situation, described in detail elsewhere (Ainsworth \& Wittig, 1969). Briefly, the procedure involves a series of eight increasingly stressful episodes designed to elicit attachment behaviors in infants.

Infants were observed in the same playroom as in Observation 1. At this time the room contained two chairs (one for the mother and one for the stranger), a table, and several toys. The Strange Situation assessment is focused exclusively on infant behaviors. Consequently, no measures were taken of mother behaviors, and mothers were instructed to respond naturally to their infants' overtures, but not to initiate any interaction. Strangers' approaches and mothers' departures were signaled by a knock on the one-way glass from the observation room. Three female student assistants served as strangers throughout the study. Determination of who would act as a stranger for any given infant was made largely on the basis of availability, but overall each 
stranger served an approximately equivalent number of times. If a student was serving as a stranger, she was not seen by the infant prior to the Strange Situation.

Response Measures for Observation 2. The Strange Situation yields three sets of response measures: a frequency count of several discrete attachment and exploratory behaviors; observer ratings on six scales designed to assess variations among infants in interaction with mother and stranger; and a classification of infants as belonging to one of three-A, B, or C-attachment categories. That latter measure, attachment classification, is accomplished through a qualitative judgment on the part of the observer, taking into account the profile of behaviors exhibited by the infant throughout the entire sequence of events, but relying heavily on the baby's response to the mother during the reunion episode. There were 17 infants classified as "A" babies ( $7 \mathrm{M} ; 10 \mathrm{~F}), 28$ classified as " $B$ " ( $11 \mathrm{M} ; 17 \mathrm{~F})$, and only two classified as " $C$ " babies ( $1 \mathrm{M} ; 1$ $F)$. The two $C$ babies were omitted from these analyses. Although the percentages of $\mathrm{A}, \mathrm{B}$, and $\mathrm{C}$ infants are somewhat divergent from those reported in earlier studies (Ainsworth et al., 1978; Waters, 1978), they correspond closely to those obtained in a recent sampling by Main and Weston (1981).

Reliability for three observers was again established by calculating a percentage of agreement ratio on all measures for all observers. Reliability for all measures was high, averaging .95 . Reliability for the attachment classification (i.e., A, B, C) was 1.00. Subclassifications were also assessed but were not used in the present analyses.

\section{RESULTS}

Intercorrelations of discrete infant behaviors at seven months with similar discrete behaviors at 13 months are presented first, followed by descriptive statistics for mother and infant 7-month behaviors in relation to attachment classification at 13 months. A series of factor analyses of both mother and infant 7-month behaviors are reported next. These were designed to explore the importance of and the relationship among the behaviors assessed in each episode (preseparation, separation, and reunion). The results of these analyses were used to determine which variables would be submitted to a series of multiple discriminant function analyses which were conducted to examine the predictability of 13-month infant attachment classification on the basis of 7-month mother and infant behaviors.

\section{Intercorrelations of Similar Discrete Attachment Behaviors at 7 and 13 Months}

Intercorrelations were performed for several comparable behaviors across the 7- and 13-month age groups, to examine the relationship between discrete variables. Vocalizing, looking at mother, smiling, approaching, touching, playing, crying/fussing, and neutral behaviors were coded and available for preseparation, separation, and reunion episodes at both 7 and 13 months. Following 
Waters (1978), discrete behaviors from preseparation, separation and reunion episodes of the Strange Situation were used in this analysis. None of the correlations were significant, reaffirming the conclusion that continuity in attachment is not reflected in intercorrelations of discrete attachment indices (i.e., Ainsworth et al., 1978; Lewis \& Starr, 1979; Waters, 1978).

\section{Descriptive Statistics}

Tables 1 and 2 provide frequencies, means, standard deviations, and $t$-statistics for mother and infant behaviors at 7 months and by infant attachment classification at 13 months. These are presented separately for each episode.

Although few mean differences reached significance, Table 1 suggests that generally mothers of A babies are less likely to vocalize to, look at, smile, touch or play with their infants during either the preseparation or reunion episodes. These mothers are more likely to read or engage in other noninteractive neutral behaviors during both episodes. The frequencies of each behavior and the percentages of the subgroups represented also suggest several interesting differences. For example, $100 \%$ of the A mothers touched their infants during the preseparation episode but only $89 \%$ of the B mothers did so. It seems noteworthy that the percentage of A mothers touching their infants at reunion decreases to $65 \%$ after the stress of separation when the complementary figure for B mothers remains exactly the same, $89 \%$.

TABLE 1

Descriptive Statistics for Mothers of A and B Infants at 7 Months

\begin{tabular}{|c|c|c|c|c|c|c|c|c|}
\hline \multirow[b]{2}{*}{ Behovior } & \multicolumn{3}{|c|}{ Preseparation } & \multicolumn{3}{|c|}{ Reunion } & \multirow[b]{2}{*}{$\begin{array}{c}\text { Mean } \\
\text { Frequency }\end{array}$} & \multirow[b]{2}{*}{$S D$} \\
\hline & $n^{\circ}$ & $\%$ & $\begin{array}{c}\text { Mean } \\
\text { Frequency }\end{array}$ & SD & $n$ & $\%$ & & \\
\hline \multirow[t]{2}{*}{ Vocalize } & A 16 & 94 & $18.1^{*}$ & 19.3 & 15 & 88 & 6.9 & 5.8 \\
\hline & B 27 & 96 & 31.2 & 22.3 & 26 & 93 & 10.9 & 9.3 \\
\hline \multirow[t]{2}{*}{ Look } & A 17 & 100 & 61.4 & 23.2 & 17 & 100 & $12.5 * *$ & 5.4 \\
\hline & B 28 & 100 & 63.1 & 23.9 & 28 & 100 & 16.0 & 2.9 \\
\hline \multirow[t]{2}{*}{ Smile } & A 10 & 59 & 2.6 & 3.2 & 5 & 29 & 1.8 & 4.4 \\
\hline & B 21 & 75 & 4.9 & 5.7 & 13 & 46 & 1.4 & 2.7 \\
\hline \multirow[t]{2}{*}{ Approach } & A 15 & 88 & 2.6 & 1.5 & 13 & 76 & 0.9 & 0.6 \\
\hline & B 23 & 82 & 2.3 & 1.7 & 22 & 79 & 1.0 & 0.6 \\
\hline \multirow[t]{2}{*}{ Touch } & A 17 & 100 & 10.9 & 11.4 & 11 & 65 & $3.0^{* *}$ & 3.7 \\
\hline & B 25 & 89 & 16.7 & 14.8 & 25 & 89 & 7.2 & 5.6 \\
\hline \multirow[t]{2}{*}{ Play B } & A 11 & 65 & 18.1 & 20.7 & 9 & 53 & $2.5^{*}$ & 3.6 \\
\hline & B 26 & 93 & 20.4 & 21.3 & 21 & 75 & 6.1 & 6.7 \\
\hline \multirow[t]{2}{*}{ Neutral/Read } & A 15 & 88 & 31.1 & 24.7 & 6 & 35 & $3.2^{*}$ & 5.7 \\
\hline & B 22 & 78 & 24.7 & 25.7 & 2 & 78 & 0.5 & 2.3 \\
\hline
\end{tabular}

a Specifically, the number of mothers emitting the behaviors at least once per episode.

b For the 15-min preseparation period for all mothers.

c For the 3-min reunion period for all mothers.

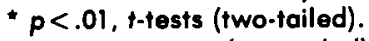

** $p<.01$, t-tests (two-tailed). 


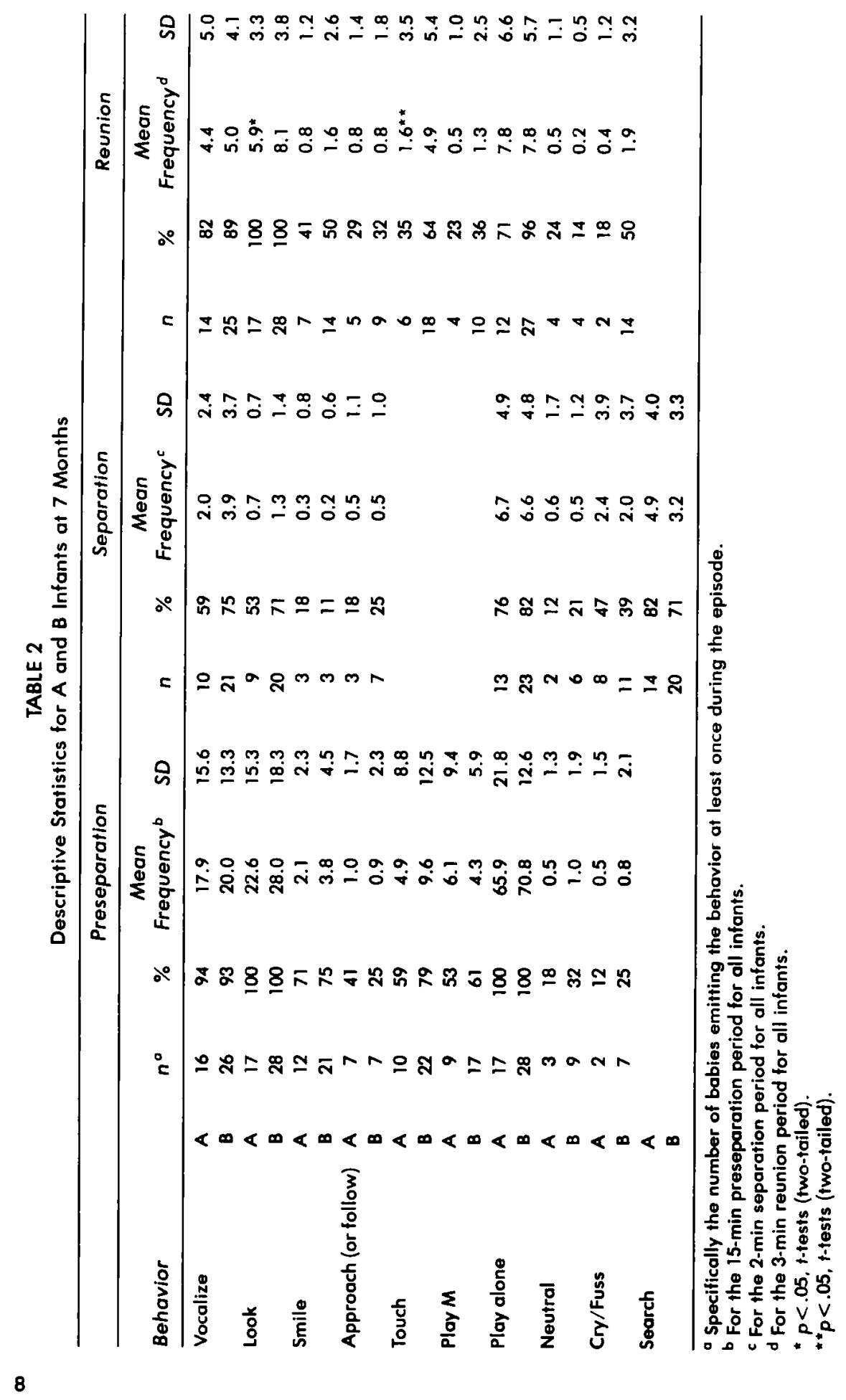


Infant behaviors also reflect some consistent differences across attachment type. A babies vocalize, look at and touch their mothers less than infants who are classified as B babies at 13 months. Again, some differences across episodes are particularly interesting. A babies are less likely to cry or fuss during the preseparation episode than B babies $(12 \%$ vs. $25 \%)$. During the separation episode, however, $47 \%$ of the A babies fuss or cry but only $39 \%$ of the B babies do. This pattern then reverses with reunion when only $18 \%$ of the $A$ babies cry or fuss but $50 \%$ of the B babies do. Thus, although these differences may not be significant in the conventional statistical sense, they do suggest a pattern or trend in the differences between behaviors emitted at seven months and later attachment classification.

Perhaps the most striking result to emerge from the analysis of discrete measures is with regard to the overall frequency of mutual interaction between $A$ and $B$ infants and their mothers during the 7-month observation. No significant difference was found for the amount of preseparation interaction. Mean preseparation interaction scores were 19.12 and 22.86 for $A$ and $B$ infants and their mothers, respectively, $t(43)=.7154$, N.S. However, B infant dyads engaged in significantly more mutual interaction during the reunion episode than did $\mathrm{A}$ infant dyads, 7.46 ( $\mathrm{B}$ infants) versus 4.71 (A infants), $t(43)=2.037$, $p<.05$.

Considering Tables $1 \& 2$ as a whole, for both mother and baby initiated behavior at seven months, only one significant difference between dyads in which infants were later categorized as Type A or Type B emerged during the preseparation and separation episodes. However, during the reunion period, there were six mother and infant behaviors significantly distinguishing the two groups. For dyads in which infants were subsequently classified as motheravoidant (A), there were significantly fewer occurrences of mother-looking, baby-looking, mother-touching, baby-touching, and mother-playing with baby, and significantly more incidences of mother engaging in neutral behavior or reading. These results suggest that the reunion episode provides a more predictive context than either of the preceding episodes for later attachment classification.

\section{Factor Analyses and Infant Behaviors at 7 Months}

In order to examine the pattern of interrelationships among the variables and to explore the possibility of data reduction, principal component analyses (PCA) were performed on mother and infant behaviors separately for each episode. A series of five unrotated PCA's were conducted on: preseparation mother behavior (PMB), reunion mother behavior (RMB), preseparation infant behavior (PIB), separation infant behavior (SIB), and reunion infant behavior (RIB).

The significant factors (defined for this purpose as those factors with an eigenvalue $>1$ ) are presented in Table 3 . Most solutions produced only one significant factor, although the analysis of reunion infant behaviors did pro- 
TABLE 3

Factor Loadings of Mother and Infant Behavior During 7-Month Visit

\begin{tabular}{|c|c|c|c|c|}
\hline \multicolumn{5}{|c|}{ Factor Loadings ${ }^{\circ}$ of Mother Behoviors } \\
\hline Behavior & \multicolumn{2}{|c|}{ Preseparation Factor 1} & \multicolumn{2}{|c|}{ Reunion Factor 1} \\
\hline Vocalize & \multicolumn{2}{|c|}{.66} & \multicolumn{2}{|c|}{.41} \\
\hline Look & \multicolumn{2}{|c|}{.91} & \multicolumn{2}{|c|}{.88} \\
\hline Smile & \multicolumn{2}{|c|}{.21} & \multicolumn{2}{|c|}{.12} \\
\hline Approach & \multicolumn{2}{|c|}{-.10} & \multicolumn{2}{|c|}{-.03} \\
\hline Touch & \multicolumn{2}{|c|}{.37} & \multicolumn{2}{|c|}{.42} \\
\hline Play & \multicolumn{2}{|c|}{.55} & \multicolumn{2}{|c|}{.41} \\
\hline Neutral/Read & \multicolumn{2}{|c|}{-.91} & \multicolumn{2}{|c|}{-.72} \\
\hline Eigenvalue & \multicolumn{2}{|c|}{2.57} & \multirow{2}{*}{\multicolumn{2}{|c|}{$\begin{array}{l}1.81 \\
25.8\end{array}$}} \\
\hline$\%$ Variance & \multicolumn{2}{|c|}{36.7} & & \\
\hline \multicolumn{3}{|c|}{ Factor Loadings ${ }^{a}$ of Infant Behaviors } & \\
\hline & $\begin{array}{l}\text { Preseparation } \\
\text { Factor } 1\end{array}$ & $\begin{array}{c}\text { Separation } \\
\text { Factor } 1\end{array}$ & $\begin{array}{l}\text { Reunion } \\
\text { factor } 1\end{array}$ & Factor 2 \\
\hline Vocalize & -.02 & -.32 & -.02 & .32 \\
\hline Look (at Mother or door) & .57 & .33 & .64 & .27 \\
\hline Smile & .31 & -.01 & .37 & .54 \\
\hline Approach (or follow) & .21 & .38 & .11 & .08 \\
\hline Touch & .54 & & .62 & -.33 \\
\hline Play M & .45 & & .52 & .23 \\
\hline Neutral behaviors & .30 & .21 & -.19 & -.04 \\
\hline Crying/fussing & .25 & .57 & .35 & -.58 \\
\hline Search & & .45 & & \\
\hline Play alone & -.74 & -.89 & -.51 & .23 \\
\hline Eigenvalue & 1.67 & 1.72 & 1.64 & 1.03 \\
\hline$\%$ Variance & 18.6 & 21.5 & 18.2 & 11.5 \\
\hline
\end{tabular}

a For only those factors with eigenvalues over 1.

duce a second factor which accounted for an additional $12 \%$ of the variance and reached significance by our definition.

As Table 3 indicates the PCA of preseparation mother behaviors yields one significant factor which accounts for $37 \%$ of the variance. The variables which load positively $(>.35$ ) on preseparation Factor 1 are looking, vocalizing, playing, and touching (variables are reported for all analyses in descending order of factor loadings). Noninteractive neutral behavior (including reading) loads negatively on this factor. The factor loadings for the analyses of reunion mother behaviors are quite similar. Looking, touching, vocalizing, and playing load positively on reunion Factor 1, with neutral/reading behavior again loading negatively. This factor accounts for $26 \%$ of the variance.

Three PCA's were conducted with the infant behaviors. The analysis of preseparation behaviors yields a factor on which looking, touching, and playing with mother load positively (>.35). Playing alone loads negatively. This factor accounts for approximately $19 \%$ of the variance. Analysis of infant separation behaviors also yields one factor accounting for $22 \%$ of the variance. 
Crying/fussing, searching, and following each load positively on this factor, whereas playing alone loads highly and negatively. Two factors emerged in the analysis of reunion infant behaviors. Factor 1 accounts for about $18 \%$ of the variance, with looking, touching, playing with mother, smiling, and crying/ fussing loading positively on this factor and playing alone again loading negatively. The second factor accounts for an additional $12 \%$ of the variance with smiling loading positively and crying/fussing loading negatively.

Since 147 mother-infant pairs were observed at 7 months, it was possible to use the split-half reliability method to examine the reliability of the factor analyses. The factor structures and the number of reliable factors that emerged from the two sets of factor analyses are remarkably consistent. The split-half reliability coefficients (Bruning \& Kintz, 1968) based on the factor scores are quite high in most cases and acceptably high in all: PMB Factor $1=.99$; RMB Factor 1=.99; PIB Factor 1=.97; SIB Factor $1=.96$; RIB Factor $1=.94$; RIB Factor $2=.77$. An additional reliability check was performed comparing the 47 infants who were part of the panel study and the 100 infants who were only part of the cross-sectional study. The results of these comparisons were still quite acceptable with the exception of the two Infant Reunion factors: PMB Factor $1=.985$; RMB Factor $1=.99$; PIB Factor $1=.94$; SIB Factor $1=.88$; RIB Factor 1=.56; and RIB Factor $2=.73$. This latter approach must be considered with some caution since one of the two groups was extremely small $(N=47)$. However, some concern was felt for the reduced reliability of the infant reunion factors. The overall results of the reliability checks prompted the next phase of the study. This involved choosing a limited number of variables on the basis of the factor loadings to include in a series of multiple discriminant function (MDF) analyses. The MDFs were used to examine the predictability of attachment classification at 13 months on the basis of mother and infant behaviors at 7 months. The results of these analyses are reported below.

\section{Multiple Discriminant Function Analyses (MDF)}

Multiple discriminant function analysis yields, for a given number of variables, an estimate of which variables in combination provide maximal discrimination between two or more groups, and of the relative weights of each variable contributing to the discrimination. The specific functions derived from these analyses could ultimately, like those derived in regression analyses, be used to increase the precision of prediction in the individual case, provided that the functions are replicated through extensive cross-validation with independent samples. A primary goal of this study was to delineate variables or combinations of variables that would have predictive utility at seven months, and to examine the influence of situational variation or context (e.g., preseparation vs. reunion) on this prediction. Although the MDF analysis assumes a multivariate normal distribution and equality of the variance-covariance matrix, the 
technique has been shown to be extremely robust.' Thus, MDF analyses were deemed to be acceptable in the present situation.

MDF analyses were conducted for mother and infant behaviors separately for the preseparation, separation, and reunion episodes. Attachment classification at 13 months was used as the criterion variable. Since only a limited number of variables could be appropriately included in the MDF analyses, the following procedure was used. The variables which obtained the five highest loadings on each of the significant factors were entered into the six separate MDF analyses. The results of these analyses are presented in Table 4. The loadings indicated in Table 4 suggest that no behavior is particularly discriminating for mothers during the preseparation period, since the loadings for all mother behaviors are less than .10, but that both looking and touching discriminate in the reunion episode. For infants, smiling and playing with mother define the preseparation period, and looking at the door dominates separation behavior with search and cry/fuss behavior also important. Touching, looking and smiling define the first reunion MDF but cry/fuss, smiling and touch load moderately on the second reunion MDF. A modest percent of the variance is accounted for by these analyses. This figure ranged from $17 \%$ to $26 \%$ as indicated by squaring the canonical correlation.

Table 5 represents a somewhat different perspective on the results from the MDFs. This table details the frequencies of correct and incorrect predictions compared with the actual distribution of $\mathrm{A}$ and $\mathrm{B}$ infants, i.e., the "hit rate." These vary considerably from $67 \%$ for Infant Preseparation Behaviors and $69 \%$ for Mother Preseparation Behaviors to 78 and $73 \%$, respectively, for Infant and Mother Reunion Behaviors. Even considering that a $62 \%$ rate of correct prediction would be obtained by chance, the rate of successful prediction for infant separation, and both mother and infant reunion behaviors is noteworthy. The prediction obtained from Mother and Infant Preseparation Behaviors, however, is not as pronounced. This result, in conjunction with the univariate findings indicating that $A$ and $B$ infants are differentiated primarily by reunion behaviors, lends considerable support to the proposition that con-

' Using other multivariate techniques, we have confirmed the results of the multiple discriminant function analyses. First, multiple regressions have been conducted for each episode using the same independent variables as the MDF analyses. The amount of variance explained in the regressions for each episode were virtually identical with the variance explained in the respective MDFs. In addition, the behaviors that load higher in the MDFs for each episode also contribute very highly to the Multiple Rs for each regression. Since a dichotomous dependent variable violates the assumption of multivariate normality and since these data were known to be somewhat skewed, we aiso explored the appropriateness of the MDF analyses. Specifically, we duplicated the regression analysis using the OSIRIS IV DREG program (Survey Research Center, 1981), which calculates a maximum likelihood regression solution for a dichotomous dependent variable. DREG, which can test either a logit or a linear model, takes into consideration the fact that the mean of a dichotomous dependent variable is restricted and that its variance may not be constant. The resuit of these analyses, using a linear model, confirmed that the multiple discriminant function technique is robust enough to provide a good solution for the data, and that a linear, additive model is appropriate. 
TABLE 4

Discriminant Function Analyses

\begin{tabular}{|c|c|c|c|c|c|c|c|c|}
\hline \multicolumn{3}{|c|}{ Mother Preseparation Behaviors } & \multicolumn{2}{|c|}{ Loadings } & \multicolumn{3}{|c|}{ Reunion Behaviors } & Loadings \\
\hline \multirow{2}{*}{\multicolumn{3}{|c|}{$\begin{array}{l}\text { Vocalize } \\
\text { Look }\end{array}$}} & \multicolumn{2}{|c|}{-.05} & \multicolumn{2}{|c|}{ Vocalize } & & -.02 \\
\hline & & & \multicolumn{2}{|c|}{.06} & \multicolumn{2}{|c|}{ Look } & \multicolumn{2}{|r|}{.16} \\
\hline Touch & & & \multicolumn{2}{|c|}{-.03} & \multicolumn{2}{|c|}{ Touch } & \multicolumn{2}{|r|}{.13} \\
\hline Play B & & & \multicolumn{2}{|c|}{.02} & \multicolumn{2}{|c|}{ Play B } & \multicolumn{2}{|r|}{-.03} \\
\hline Neutral/Read & & & \multicolumn{2}{|c|}{.04} & \multicolumn{2}{|c|}{$\begin{array}{l}\text { Neutral/Read } \\
\text { Canonical } r\end{array}$} & \multicolumn{2}{|r|}{-.01} \\
\hline Canonical $r^{\circ}$ & & & \multicolumn{2}{|c|}{.41} & \multicolumn{2}{|c|}{ Canonical $r$} & \multicolumn{2}{|r|}{.51} \\
\hline Component $^{b}$ & & & \multicolumn{2}{|c|}{.20} & \multicolumn{2}{|c|}{ Component } & \multicolumn{2}{|r|}{.35} \\
\hline \multicolumn{4}{|c|}{$\begin{array}{l}\text { Infant } \\
\text { Preseparation Behaviors Separation }\end{array}$} & \multicolumn{3}{|c|}{ Reunion, $\mathrm{Cl}$} & \multicolumn{2}{|c|}{ Reunion, C2 } \\
\hline Play alone & .03 & Play alone & .04 & Look & & .13 & Cry/fuss & .23 \\
\hline Look & .03 & Cry/Fuss & .16 & Touch & & .16 & Smile & .20 \\
\hline Touch & .06 & Search & .22 & Ploy $M$ & & -.03 & Touch & .12 \\
\hline Play M & -.11 & Follow & .07 & Play & & .06 & Vocalize & .03 \\
\hline Smile & .17 & Look & -.82 & Smile & & .12 & Look & .04 \\
\hline Canonical r & .48 & Canonical $r$ & .44 & Canoni & al $r$ & .41 & Canonical $r$ & .46 \\
\hline Component & .29 & Component & .24 & Compo & ient & .20 & Component & .27 \\
\hline
\end{tabular}

- Canonical $r$ is the maximum correlation between o linear function of the predictor set and the criterion (Cooley \& Lohnes, 1971).

b The Component $(\lambda)$ is the eigenvalue for the discriminant function. The relationship between the Cononical correlation and the eigenvalue is: Canonical $r=\sqrt{ } \lambda_{i} /\left(1+\lambda_{t}\right)$ where $i$ is the associated discriminant function (Klecka, 1980).

TABLE 5

Correct Versus Incorrect Predictions on the Basis of the MDF Analyses

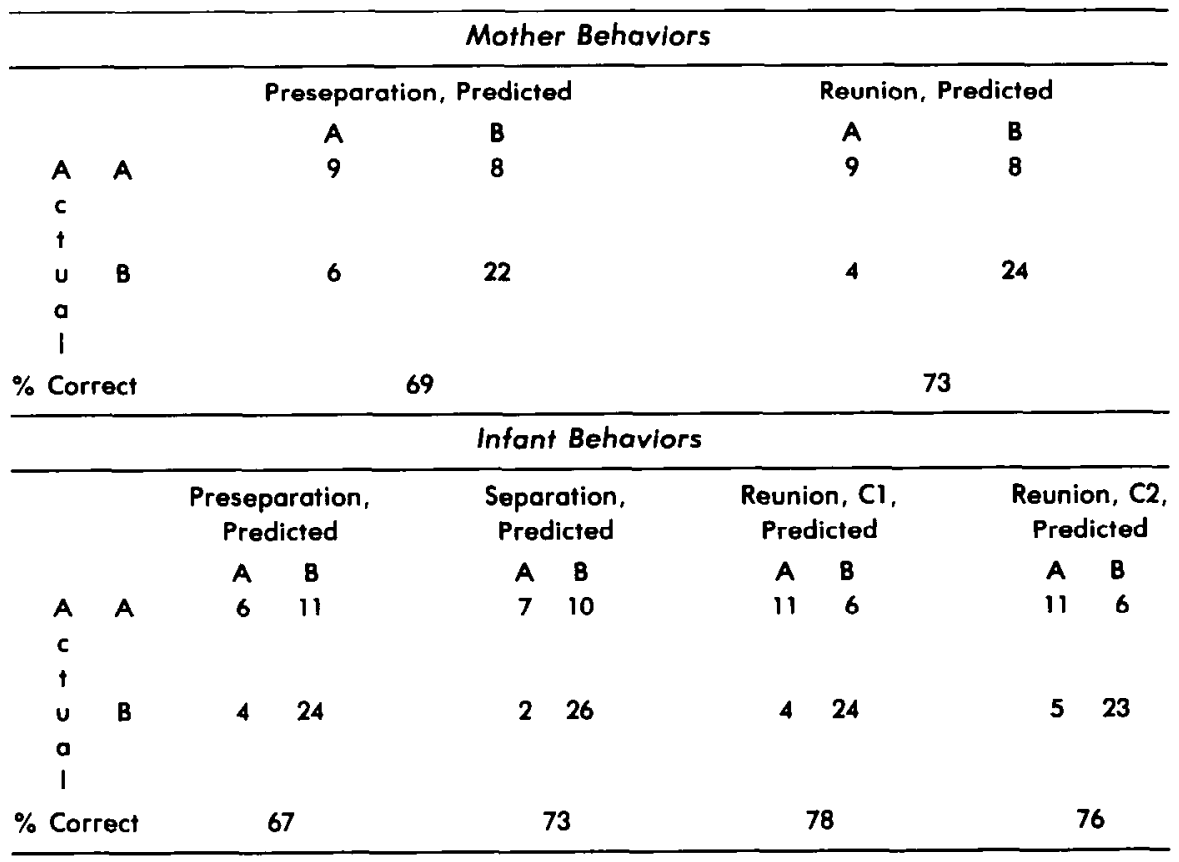


text is important to the assessment of attachment and reaffirms the salience of separation and reunion behaviors as indices of attachment quality.

Unfortunately at the present time there is no exact test of significance of the "hit rate" for an MDF. However, Rulon and Brooks (1968) suggest that in the special case of an MDF with two groups, a regression analysis will yield a test of the significance of the Wilkes Lambda. Although this is not exactly a test of the frequencies of correct and incorrect predictions compared with the actual distribution of $A$ and $B$ infants, it does test the degree to which the function discriminates between the two groups. Regression analyses were performed for each MDF analysis. These analyses suggest that only the Mother Reunion function significantly discriminates between the two groups, $F(5,44)=2.72$, $p<.03$.

\section{DISCUSSION}

There were a number of specific issues regarding the study of attachment addressed in this investigation. These include: (a) the stability and predictive value of discrete measures; (b) the possibility of developmental transformations in attachment indices; (c) the utility of a multivariate approach to the study of attachment over time; (d) the influence of context; and (e) the significance of early dyadic interaction as a predictor of attachment security.

With regard to the first issue, the results of this study confirm reports by previous investigators regarding the instability of discrete measures of attachment (Coates et al., 1972b; Masters \& Wellman, 1974; Waters, 1978). There were no significant intercorrelations in either identical or related measures from 7 to 13 months.

The results also suggest some support for the proposal that transformations occur over time in topographical features indexing the attachment relationship (Lewis \& Ban, 1971; Lewis \& Starr, 1979). For example, the most salient index distinguishing $A$ and $B$ infants in the Strange Situation is a rating of the degree to which infants avoid the mother at reunion. However, despite the fact that it would have been possible for infants to display this behavior within the context of the analogous separation and reunion situation, virtually no incidence of mother avoidance was observed in the 7-month sample. Perhaps the relative inattentiveness and diminished interaction observed between $A$ infants and their mothers at reunion is a forerunner of later avoidance. Active avoidance of the mother, then, is probably a behavior that develops later in the baby's repertoire (see Main \& Weston, 1982, for a more extensive treatment of avoidance behavior). It is conceivable that this behavior emerges along with a general tendency to take a more active role in regulating or controlling social interaction, as in the avoidance of strangers often observed in infants beginning at 8 to 10 months (see Levitt, 1980; Sroufe, 1977).

The utility of the multivariate procedures used in this study has been demonstrated in the prediction of Strange Situation classification through discriminant function analysis. In addition, the value of the factor analytic technique employed in the task of data description and reduction deserves emphasis. 
The dominant factors emerging from these analyses seemed to be definable as general interactive factors, with high positive loadings for both mothers and babies exhibited by variables indicating proximal involvement (e.g., touching and interactive play) and high negative loadings by noninteractive variables (e.g., mother reading and baby playing alone). Variables suggesting distal involvement with infants also loaded highly on the analyses of maternal behavior (e.g., vocalizing and looking at baby).

One secondary factor emerged in the analysis of infant reunion behavior. This factor too seemed to be defined by distal behavior (vocalizing and smiling in the absence of touching). However, caution should be exercised in interpreting the infant reunion factors since these may be less reliable. For both mothers and infants, then, the predominant response to the playroom situation seemed to be to attend to and interact with each other, though the more complex factor structure at reunion suggests more variability in response by infants to that situation. This alteration in factor structure following separation from the mother is one indication that the 7 -month-old babies were sensitive to the context of the situation. Other indicators of this sensitivity, and of the importance of context to the prediction of Strange Situation classification, are discussed below.

It would have been advantageous to compare factor structures on identical variables from 7 to 13 months. However, the limited size of the 13-month sample precluded this approach, and, at the same time, necessitated a reduction in the number of variables used as predictors in the discriminant analyses. The current procedure allowed the prospective identification of variables that contributed significantly to the variance among infants and mothers at 7 months, and an assessment of the degree to which these variables, in combination, discriminated between potential A and B babies at 13 months. The particular variables used in the analyses, then, were derived independently of their relationship to the criterion. It can be argued that this type of analysis is a useful adjunct to approaches relying solely on intuitive selection of measures, or on retrospective identification of relationships between data obtained at different points in time.

As indicated earlier, the influence of context on the behavior of mothers and infants in the 7-month situation and on the degree to which this behavior proved to be predictive of 13-month classification was readily apparent in these analyses. The change in infant factor structures for these episodes has already been noted. In terms of individual variables as well, infants tended to play more prior to separation but cry more and play less following separation. This finding is consistent with observations of older infants in the Strange Situation; that is, infants typically display increasing distress and reduced exploration in that situation.

It is also interesting to note responses to the separation itself. One factor emerged as dominant in the analysis of infant separation behavior. This factor was defined by variables that are clearly suggestive of separation distress, including looking at the door, following the mother as she left the room, crying 
and fussing, and absence of play. Thus, it is probable that these infants at seven months were responding to separation from the mother, and to the subsequent reunion with her, in ways that foreshadowed, but were not identical to, patterns that these infants would later exhibit in the Strange Situation.

Further consideration of the results of these analyses leads us to the conclusion that not only were infants sensitive to variations in situational context at 7 months, but also that the predictive value of the behavior of babies and their mothers at this time was dependent on the situation. With regard to infants, separation and reunion behaviors proved to be the most robust predictors of 13-month classification. This result is consistent with the observation that, with regard to the Strange Situation, differences among infants in attachment quality are reflected primarily in separation behavior of infants and reunion behavior (Ainsworth et al., 1978; Waters, 1978).

Although the behavior of mothers both prior to and following separation at 7 months was discriminative of infant classification, the greater salience of mothers' reunion behavior is suggested by the significant $F$ test in the regression analyses, by the higher canonical correlation of reunion variables with infant classification status, and by the proportion of individual reunion variables differentiating between $A$ and $B$ infants. Significant differences between $A$ and $B$ babies were found for 4 of 7 mother-behavior variables coded at reunion. Mothers of B infants looked at, touched, and played with their infants significantly more at reunion than did mothers of A infants. Mothers of B infants were also significantly less likely to read or engage in other behavior not directed toward their infants. Thus, while these same variables in combination were predictive of infant classification regardless of whether they had occurred pre- or postseparation, it was the frequency of occurrence for these behaviors at reunion that carried more weight in the analyses.

The influence of context is also apparent in terms of the overall frequency of interaction engaged in by the mother-infant dyads prior to and following separation. While the amount of preseparation interaction did not distinguish $A$ and $B$ infants, the differences between these infants and their mothers were quite pronounced at reunion, with $B$ infants and their mothers engaging in significantly more reciprocal interaction during this episode than did A infants and their mothers.

All of these findings taken together raise questions regarding the direction of effects in the 7-month situation. For example, one might wish to know whether the mothers of $B$ infants tended more than mothers of $A$ infants to initiate and maintain contact with their babies, or whether the infants themselves elicited this behavior through crying or other means of promoting contact. Some support for both of these alternatives can be found in the pattern of results characterizing these data. The single significant $F$ test for mother reunion behaviors and the relatively high "hit rate" for mother reunion behaviors, however, does suggest that mothers may be differentially and more consistently contributing to this behavior pattern. Unfortunately, without the 
aid of sophisticated monitoring equipment, it proved impossible to detect reliably the direction of effects within the interactions observed. Thus, we do not know whether particular incidences of interaction were baby or mother initiated or terminated. It seems, at least at the molar level, that the bulk of these interchanges were of the type characterized by Gewirtz and Boyd (1976) as strong reciprocal interactions, for which the antecedent and consequent components are difficult to identify. Research by investigators endeavoring to relate early microanalytic interaction to later attachment security, such as that currently in progress by Tronick (1980) and Beebe (personal communication, 1982 ) should prove enlightening. Meanwhile, it is striking that both the overall frequency of interaction and the discriminant functions derived from the behavioral components of that interaction for a 3 -min reunion episode at 7 months should differentiate infants later identified as securely and insecurely attached.

In conclusion, the results of this study identify some early predictors of attachment security and reinforce the value of multivariate analysis in detecting relationships and continuities among attachment indices not necessarily revealed by focusing on single discrete measures. Further exploration along these lines may prove to be propaedeutic to a more thorough delineation of the attachment construct, and to a greater understanding of developmental changes in attachment behavior.

\section{REFERENCES}

Ainsworth, M. D. S. (1969). Object relations, dependency, and attachment: A theoretical review of the infant-mother relationship. Child Development, 48, 969-1825.

Ainsworth, M. D. S. (1973). The development of infant-mother attachment. In B. M. Caldwell \& H. N. Ricciuti (Eds.), Review of child development research (Vol. 3). Chicago, IL: University of Chicago Press.

Ainsworth, M. D. S., Blehar, M. C., Waters, E., \& Wall, S. (1978). Patterns of attachment. Hillsdale, NJ: Erlbaum.

Ainsworth, M. D. S., \& Wittig, B. A. (1969). Attachment and exploratory behavior of one-yearolds in a strange situation. In B. M. Foss (Ed.), Determinants of infant behavior (Vol. IV). London: Methuen.

Arend, K., Gove, F. L., \& Sroufe, L. A. (1979). Continuity of individual adaptation from infancy to kindergarten: A predictive study of ego-resiliency and curiosity in preschoolers. Child Development, 58, 958-959.

Blehar, M. C., Lieberman, A., \& Ainsworth, M. D. S. (1977). Early face-to-face interaction and its relation to later infant-mother attachment. Child Development, 48, 182-194.

Bowlby, J. (1969). Attachment and loss: Vol. 1, Attachment. New York: Basic Books.

Bruning, J. L., \& Kintz, B. L. (1968). Computational handbook of statistics. Glenview, IL: Scott, Foresman.

Coates, B., Anderson, E. P., \& Hartup, W. W. (1972a). Interrelations in the attachment behavior of human infants. Developmental Psychology, 6, 218-238.

Coates, B., Anderson, E. P., \& Hartup, W. W. (1972b). The stability of attachment behaviors in human infants. Developmental Psychology, 6, 231-237.

Cooley, W. W., \& Lohnes, Paul R. (1971). Canonical correlation. Multivariate data analysis. New York: Wiley. 
Gewirtz, J. L., \& Boyd, E. F. (1976). Mother-infant interaction and its study. In Reese, H. W. (Ed.), Advances in child development and behavior (Vol. 2). New York: Academic Press.

Klecka, W. R. (1980). Discriminant analysis. Sage University paper series on quantitative applications in the social sciences. Beverly Hills, CA: Sage.

Levitt, M. (1980). Contingent feedback, familiarization, and infant affect: How a stranger bccomcs a fricnd. Developmental Psychology, 16, 425432.

Lewis, M., \& Ban, P. (1971, April). Stability of attachment behavior: A transformational analysis. Paper presented at the Society for Research in Child Development Meetings, Symposium on Attachment: Studies in Stability and Change, Minneapolis, MN.

Lewis, M., \& Starr, M. D. (1979). Developmental continuity. In J. D. Osofsky (Ed.), Handbook of infant development. New York: Wiley.

Londerville, S., \& Main, M. (1981). Security of attachment, compliance, and maternal training methods in the second year of life. Developmental Psychology, 17, 289-299.

Main, M., \& Weston, D. R. (1981). The quality of the toddler's relationship to mother and father: Related to conflict behavior and the readiness to establish new relationships. Child Development, 52, 932-948.

Main, M., \& Weston, D. R. (1982). Avoidance of the attachment figure in infancy: Descriptions and interpretations. In C. M. Parkes \& J. Stevenson-Hinde (Eds.), The place of attachment in human behavior. New York: Basic Books.

Masters, J., \& Wellman, J. (1974). Human infant attachment: A procedural critique. Psychological Bulletin, 81, 218-237.

Matas, L., Arend, R. A., \& Sroufe, L. A. (1978). Continuity of adaptation in the second year: The relationship between quality of attachment and later competence. Child Development, 49, 547-556.

Rulon, P. J., \& Brooks, W. D. (1968). On statistical tests of group differences. In D. K. Whitla (Ed.), Handbook of measurement and assessment in the behavioral sciences. Reading, MA: Addison-Wesley.

Schaffer, H. R., \& Emerson, P. E. (1964). The development of social attachments in infancy. Monographs of the Society for Research in Child Development, 29(3).

Sroufe, L. A. (1977). Wariness of strangers and the study of infant development. Child Development, 48, 731-746.

Sroufe, L. A., \& Waters, E. (1977). Attachment as an organizational construct. Child Development, 48, 1184-1199.

Stayton, D. J., \& Ainsworth, M. D. S. (1973). Individual differences in infant responses to brief, everyday separations as related to other infant and maternal behaviors. Developmental Psychology, 9, 226-235.

Survey Research Center Computer Support Group (1981). OSIRIS IV user's manual. (Computer program manual). Institute for Social Research, The University of Michigan, Ann Arbor, MI.

Tronick, E. (1980, December). The infant's emotional reactions to changes in mother's behavior. Paper presented at a Symposium on Affective Displays of High-Risk Infants, held at the Mailman Center for Child Development, Miami, FL.

Waters, E. (1978). The reliability and stability of individual differences in infant-mother attachment. Child Development, 49, 483-494. 